\title{
Understanding Labor Problems and the Social Consequences of Child Labor in Pakistan
}

\author{
Khalid Mehmood Iraqi Muhammad Naeem Akhter Syed Shahid Zaheer Zaidi \\ Department of Public Administration \\ University of Karachi
}

\begin{abstract}
Pakistan during the past nearly five decades has experienced various economic hardships and the consequent social complexities. The rapidly and constantly rising population of Pakistan together with the low rate of literacy has given rise to unemployment. Despite introduction of labor policies, the conditions of labor are far from being termed as satisfactory. The impact of labor policies and their non-implementation in true sense has developed serious socio-economic issues in Pakistan. Child labor is one of those grave issues that need serious attention not only by the government but also by the people themselves. Low rate of literacy does play significant role in this issue. This paper discusses the concern of child labor, which in the present era has emerged as a serious human rights issue, with focus on the influence of labor policies of Pakistan on child labor.

Keywords: labor, child labor, socio-economic conditions
\end{abstract}

DOI: $10.7176 / \mathrm{PPAR} / 9-3-15$

Publication date:March $31^{\text {st }} 2019$

\section{Introduction}

Pakistan since 1960s has faced severe economic challenges for various reasons. Despite having a large size of population, attention has been lacking on turning its people into a proper workforce and human resource. The labor policies designed from time to time in Pakistan have not been effectively implemented with the outcome that there are a number of issues in the administration of labor while the satisfaction is nearly unknown to most of the labor force. The impact of this issue has taken child labor also into its fold. Poverty is the basic cause of child labor. Children have to earn money to substantiate the insufficient and appalling family income. In many cases they have to work because they cannot afford to go to school. It always carries a heavy price tag to send children school in the form of transport, uniforms and books cost, generally not bearable by poor parents since they do not have adequate resources. On the other hand, parents anticipate that their children contribute to the household budget by bringing in money.

As for Pakistan, it has been assumed in the Factories Act 1934 (www.ma-law.org.pk/pdflaw/FACTORIES) that no individual under the age of 12 years can be employed in any factory, but any person below the age of 15 years would be taken care of as child. Those who are 15 but below 17 years of age are treated as adolescent (Shaeed, 2007). No child or adolescent can be employed in a factory unless and until he is in possession of a certificate of fitness obtained from certifying surgeon. No child is allowed to work in a factory for more than 5 hours in any day and total spread over should not exceed $7 \frac{1}{2}$ hours. If a child over the age of 6 years is found inside any part of a factory in which children are working, he shall until the contrary is proved, deemed to be working in the factory. In Pakistan people are not following this law and in many places you will find that most of the children, who are working in different places, are below the age of 12 years (en.wikipedia.org/wiki/Child_labour_in_Pakistan). Those who are over the age of twelve are treated as adults. The need and importance of prohibiting the employment of children in factories and other industries at a tender age when they ought to be attending schools hardly requires any stress. The role of elementary education would provide enough opportunities to the children who would be in a position to shoulder greater and more important responsibilities for building up a brighter and prosperous future. Child labor is a serious problem and puts emphasis on the implementation of Child Employment Act 1991. Behind the child Labor, the two major reasons are (i) the devastated economy; (ii) the low literacy rate. The problem of literacy is directly proportional to the economy. Unless the economy improves, literacy rate cannot be improved. Due to sheer poverty parents do not find it possible to enroll their children in school and also to bear the burden of educational expenses and, therefore, are constrained to send their children to work to supplement their income.

\section{Objectives of the study}

- The purpose of this paper is to highlight the issue of child labor in Pakistan which practice largely contradicts the human rights

- To find out to what extent the labor policies of Pakistan are under political influence

- The paper sheds focused light on the impact of labor policies on child labor

- To develop and refresh awareness among the people about the consequences of child labor on the socio- 
economic condition of the society and the nation at large

- To learn about the gap between labor policy implementation and child labor in Pakistan

\section{Research Questions:}

The study will answer followings questions.

- What is the status of labor policy exercised in Pakistan?

- What impact does the labor policy in Pakistan place on the issue of child labor?

- What is prospects of children without education in Pakistan?

- What type of labor administration can be effective in Pakistan?

\section{Methodology}

While the content of the paper mainly bases on qualitative method of research, it partially contains quantitative research based on data collected for the purpose of fortifying the reliability of the information and statistics for the research. As such the method applied is a combination of the two methods (qualitative and quantitative) of research. The closed-ended items of the questionnaire facilitated the respondents in sharing their responses in a systematic manner along with comments, if any. As for qualitative data, these were attained through oral inquiries and conversations with the respondents. The data collected have been shown in the form of tables and graphics. In order to develop a representative sample of the population the research has attempted at embracing respondents from every section of the labor market in Pakistan. Out of the 300 respondents: Forty percent (120 respondents) were the labors working in various sectors; thirty percent ( 90 respondents) of the respondents were the line managers and supervisors; thirty percent ( 90 respondents) were the members of different labor organizations and unions. A survey was conducted to extract the relevant and valid data for the meaningful evaluation of the topic. For this research, a questionnaire comprising closed-ended items was designed, which aimed at collecting reliable information from the respondents. The author has used the findings extracted from his own doctoral thesis being submitted along with the acceptance of this research paper. The contents of the thesis have been checked for plagiarism already by the QEC of the University of Karachi.

\section{Hypotheses}

Considering the review of literature, random observations and opinion of knowledgeable persons, hypothesis stated below are developed:

- Hypothesis-1. The existence of child labor in Pakistan has more economic reasons as compared to political reasons.

- Hypothesis-2. In Pakistan more emphasis been given on formulating the labor policies compared to the emphasis on implementing the policies.

\section{Literature Review}

In Pakistan, in the field of production, marketing, Finance, Accounting, Engineering and other various fields, problems have been successfully overcome through the development and application of various appropriate technologies and through the development of professional expertise in all the relevant fields, but the field of Labor Management Relations has been one of the neglected fields so far. The development of concept of social justice has given rise to more sensitive and complicated problems concerning labor administration affairs (Charland, C. 2007).

Labor can be viewed as a synonym to human resource (Pant, 1972). In a narrower sense labor includes only those civilian workers who work for others and are not engaged in the work of supervision and management. Before the advent of the Industrial revolution, craftsmen were the masters of their own. They were independent in the sense that they owned their tools, raw materials. They worked according to their convenience and sold their goods in the market on a barter system. They had the satisfaction of knowing all aspects of their trade and could produce and market their goods as a whole without depending on others. In a rural economy their wants were few and limited. Between 1780 to 1900 in America, women and children had to work long hours doing hard type of labor in harmful conditions in factories that, too, again very low wages (Baird, 1984). Though the workers got employment without much difficulty in the initial stages, but their employments were neither secure nor steady. They are usually prone to periodic un-employment and under employment as a result of overproduction or adverse economic trade cycles (Mathias \& Nikolaj, 2005). Although there have been many developments in labor policies all around the world especially since the $1^{\text {st }}$ May of 1886 in Chicago, the labor in the developing countries faces many hardships (Flanagan, 2006).

A significant part of the child population in Pakistan today live in an environment very different from that used to be some decades ago. Increasing poverty together with low literacy rate and increased urbanization has added to socio-economic problems for the people. These factors have also raised environmental pollution and 
related health hazards for children (Nararsaiah, 2006). According to the definition worked out by the International Labor Organization - ILO, Child labor refers to engaging kids in any kind of job that denies them enjoy their childhood, causes them to remain away from regular schooling, and is considered for them harmful and a threat in terms of physical, psychological and social aspects. Children under fifteen, who are compelled to work, fall in Child Labor category. Parents who stay home and send their children to work in so far as aids in the former's job are an exemption as these offspring are not dispossessed of the prospect of attaining schooling facilities" (ILO, 2003).

Pakistan has been ranked as having the third largest child workforce in the world (Yaruq Malik, 2016). According to National Child Labor Survey, 1996, 3.3 million underage individuals were employed in Pakistan. While a drastic increase was reported by ILO, in 2012, that around 12.5 million juveniles in Pakistan were tangled in child labor of age between 10-14 years (DAWN, 2016). Moreover, its aftermath on health of a child is very important to take in account which may disable the child physically or mentally. There are two types of child labor, formal and informal. Sector exploration showed that only a minority worked in the official division (fabric, leather, drugs, athletic and operating devices industries), rest worked in the informal sector (cultivation business, carpeting industry, cafes, road labors and tramps). Bonded industry and domestic juvenile labor are also chief informal subdivisions in Pakistan. In my opinion, we are putting in little effort in determining the reasons leading to this social problem. There are numerous socio-economic factors that elicit child labor such as poverty, parental illiteracy, family size, traditional factors, corruption, civil war, and the dispute of inexpensive employment- making this problem even more complex. In an economy where there is a fight to compete, by deteriorating labor budget, juvenile labor is rampant. Children are employed in variety of trades such as shoeshiners, newspapers, rag- pickers, waiters, and many more (Vadsaria, 2018). It is found that in most cases children provide workforce specifically to be paid the money desired for attending the school. However, the excellence of education is frequently so unfortunate that it fails to come anyway near to the expectations and futuristic desire of the parents; and based on the further they experience so, the stronger their conviction is that children having attended school get no better opportunities than children who have no schooling. The size of the family also matters as there would be more mouths to feed in a larger family. Decline in birth rate in a specific region results in child labor decline in accordance with the birth control programs. Besides these obvious causes, employers of children maintain that they are more pertinent than grownups for works like pottery making, glass blowing and carpet-weaving, additionally they are obedient and cheaper (Hindman \& Hindman, 2009).

To give children an opportunity to self-fulfillment, education is an indispensable element. The WCL has also sanctioned the inevitability of promoting the education potentials accessible to children and to convince parents of their errands and responsibilities towards their offspring. Removing Child Labor instantly is arduous task and therefore as an alternative of having substitute to safety procedures and to insist on the instantaneous splurging, a better approach would be to look for gradual steps like counseling initiatives, legal recourses, stronger connection in the areas of education in general, assisting exceedingly poor families, etc (Bhargava, 2003).

The people affected by past or continuing disadvantage or discrimination in employment comprise Equal Employment Opportunity (EEO) groups. As a result, these groups of women, members of racial, ethnic, and ethno-religious minority groups and people with a disability, are more likely to be unemployed or work in lower paid jobs (Syed, 2003). Child labor has deleterious consequences for the child and society. Primarily, child labor will transmute into raw labor and secondly, it will lead to an escalation in delinquency where we are already facing the menace of street crime. Moreover, Child labor creates and perpetuates poverty. Additionally, the economic consequences of juvenile industry are enormous. These effects include unemployment, insufficient wage rates, limited human capital, and diminishing international trade, slow technological progress. Putting children to labor results in depriving them from learning and becoming independent beings. Resultantly, many children in Pakistan remain from growing as independent individuals for which the prevalent patriarchal control is seen as a significant reason. These children, both boys and girls, are forced to collecting vegetable waste, working in auto and motorcycle mechanic shops, making chapattis, as street vendors selling small items, carpet weaving industry and several other meager jobs (Alain Lefebvre, 1995). In recent years many children are seen collecting polythene shoppers and bags which are recycled in plastics industry. A menace to society (http://www.un.org.pk/pakistans-street-children/), child labor is not only depriving the children from their basic rights but also damaging the future generation of the countries. In many countries throughout the world it has reached to startling magnitudes. Forced to work in extremely embarrassing, and harsh conditions of exploitation, millions of children around the globe suffer physically, mentally and morally. The World Confederation of Labor - WCL had already passed a resolution on child labor thereby providing an appropriate platform to embark on the journey of safe and prosperous childhood for next generation. It was to raise awareness and spark-off at an assortment of echelon which serves as a societal mobilization for childhood fortification. This resolution invites the members to initiate steps in the ground and put forth demand son their relevant country wide establishments to renovate the national laws to safeguard the childhood labor in accordance with the whims and 
notions of the international directives and regulations. (Scholte \& Schnabel, 2002).

Following questions relevant to labor and child labor were part of the survey questionnaire while the respondents had the options to agree, disagree or express neutral opinion:

1 What is the major inclination of labor administration in Pakistan (political influence, social structure or any other)?

2 What type of labor administration would be effective in Pakistan?

3 Do you see major improvement in labor administration in near future in Pakistan?

4 Have the labor polices in Pakistan been successful in solving the issues of child labor in Pakistan?

Data comprising the responses received revealed as follows:

\section{Trend of Labor Administration in Pakistan}

Table 1

\begin{tabular}{|l|l|}
\hline Q. 1 & The major inclination of labor administration in Pakistan is towards: \\
\hline Political influence & $55 \%$ \\
\hline Social Structure & $35 \%$ \\
\hline Any Other & $10 \%$ \\
\hline
\end{tabular}

Figure 1: Inclination of Labor Administration in Pakistan

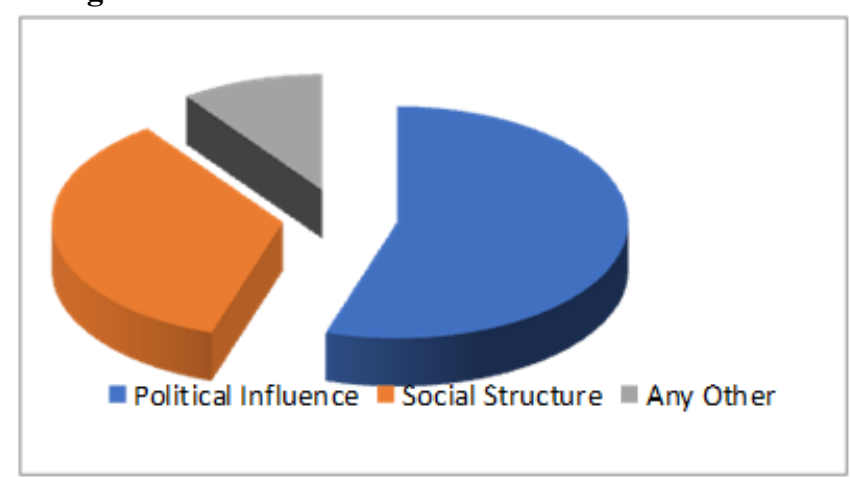

It came to observe that 55 percent of the respondents were of the view that labor administration in Pakistan have inclined towards political influences when asked about to give their opinion, whereas $35 \%$ responded with a view that social structure has been able to attract much of the attention of the labor administration in Pakistan and 10 percent of the respondents have found the interest of the labor administration somewhere else.

The labor administration has to identify its focus area which in Pakistan has been focusing towards accessing political mileage as against social or economic gains. Labor policies and labor administrations have remained true victims of political instability. Labor driven politics is one of the popular slogans in our society but still the labor fraternity has not been able to get what have been promised for. Policies and administration have been designed and implemented more to foster the political affinity rather augmenting the socio-economic wellbeing of the labor class. There is no denial from the fact that political support is sought by labor administration in other economies of the world too but it has to go beyond slogans and discussions. However some of the respondents were of the opinion that social incentives are not been focused by the labor administration in Pakistan. 65 percent of the respondents were of the view that labor administration in Pakistan have been failed to focus enough on social structures. The irony of the fact is labor fraternity in Pakistan are at the lowest ebb of socio-economic wellbeing ladder having all types of frustration and feeling of depravity. The study is of the opinion that labor administration in Pakistan needs to re-evaluate its policies and implementation of the policies should be monitored closely as there had been numerous useful policies being inked every now and then, but the problem is with the implementation of these policies. It has been a well known fact that when it comes to enforcement of policies, there is a high degree of variations and as a result, the policies instead of acting as an incentive for the improvement become a tool for their exploitation by the policy implementers.

\section{Labor Administration Type}

Table 2

\begin{tabular}{|l|l|}
\hline Q. 2 & What type of labor administration would be effective in Pakistan? \\
\hline Humanistic & $33 \%$ \\
\hline Authoritative & $41 \%$ \\
\hline Combination of both & $26 \%$ \\
\hline
\end{tabular}


Figure 2: Labor Administration Type in Pakistan

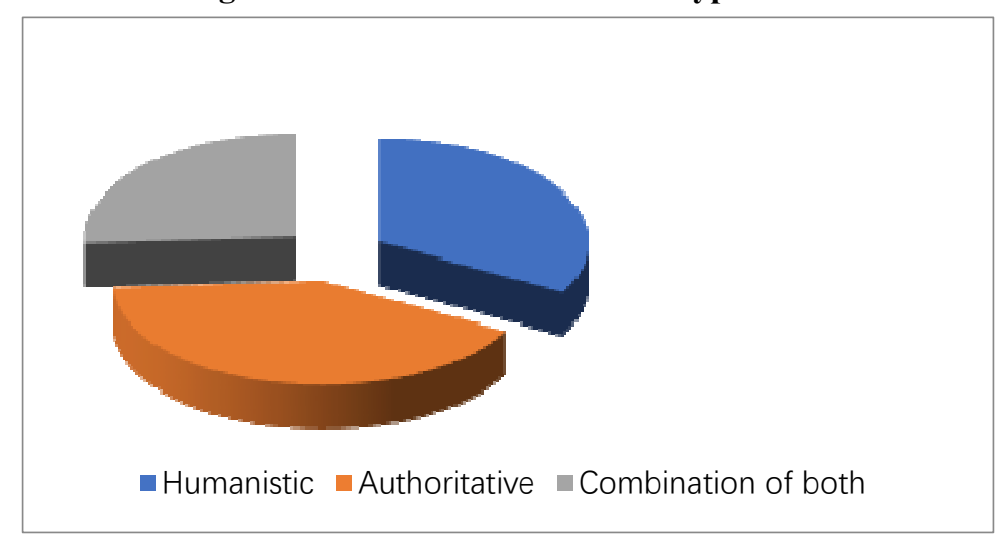

On the question on what type of labor administration would work for the economy of Pakistan, $41 \%$ believe that it has to be authoritative, $33 \%$ want it to be humanistic whereas $26 \%$ were in favor of a combination of both. Those who supported the authoritative stance were of the opinion that throughout the history it has been observed that the productivity of the economy shown significant improvement during the time when the economy experienced authoritarian rule. In their opinion labor fraternity have been exploited most by the civilian governments and they have driven away from their actual role and used for political mileage and given unfair directions. So in order to keep them on track and make them count towards the economic development, they must be dealt with authoritarian administration. This however does not mean that they should be deprived of their rights but instead mean to keep them focused on the task at their hands in order to brought major uplift in the overall performance of the labor market. Some on the other hand are much more cautious and have the opinion that a more humanistic approach of administration would do wonders. They were of the opinion that since the labor fraternity is already facing harsh facts of life which has made them more frustrated and dejected, a more humanistic administration can motivate them to work with free mind and give efficient results. They were of the view that no doubt economy has shown positive signs; but what pulls the market down is the feeling of alienation of its citizen. If labor administration not been able to made labor feel part of the whole progress and positivity the condition of growth may not stand long. However, a good number of respondents also felt that the economy needs to have a labor administration which can identify the right mix of the two approaches and have to consider that neither authoritarian nor humanitarian approach work but a balance of the two would.

\section{Improvement in Labor Administration in Pakistan}

Table: 3

\begin{tabular}{|l|l|}
\hline Q. 3 & Do you see major improvement in labor administration in near future in Pakistan? \\
\hline Agree & $52 \%$ \\
\hline Disagree & $41 \%$ \\
\hline Neutral & $07 \%$ \\
\hline
\end{tabular}

Figure 3: Future Prospects of Labor Administration in Pakistan

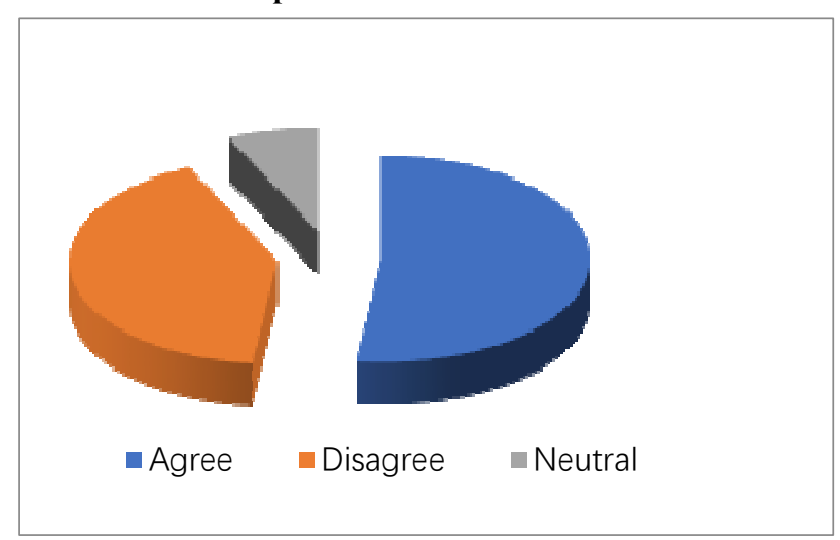

The results of the questionnaire conducted indicate that 52 percent of the respondents were of the opinion that they are optimistic about the improvement of labor administration in Pakistan, whereas 41percent of the respondents do not have high hope about improving labor administration in Pakistan and seven percent of the respondents do not hold any opinion about the chances of improvement and remain neutral. The respondents in general were of the opinion that in Pakistan low interest and will of the political leadership can be a reason to 
believe that chances of improvement are slim. They argued that what goes around comes around, indicating that when political leadership has low interest in the application of their manifesto related to labor administration then how can the economy could expect to do positives for the labors. They were of the belief that sincere effort for the improvement of labor administration cannot be possible without due political will and commitment.

However, some of the respondents were of the opinion that even though the evidence of improvement in labor administration are weak but since they are in the right direction, still a ray hope is there that soon the economy would see significant improvement in the labor administration. Furthermore they pointed out that the not only the internal environment but international pressure would compel the situation to improve. With the kind and level of foreign investment pouring in to the economy, soon the system and methods of labor administration would be transformed in conformity with the international standards.

\section{Solution of Child Labor and Gender Discrimination}

Table 4

\begin{tabular}{|l|l|}
\hline Q.6 & $\begin{array}{l}\text { Labor polices in Pakistan have been successful in solving the issues of child labor in } \\
\text { Pakistan? }\end{array}$ \\
\hline Agree & $30 \%$ \\
\hline Disagree & $68 \%$ \\
\hline Neutral & $02 \%$ \\
\hline
\end{tabular}

Figure 4: Labor Policies and Child Labor in Pakistan

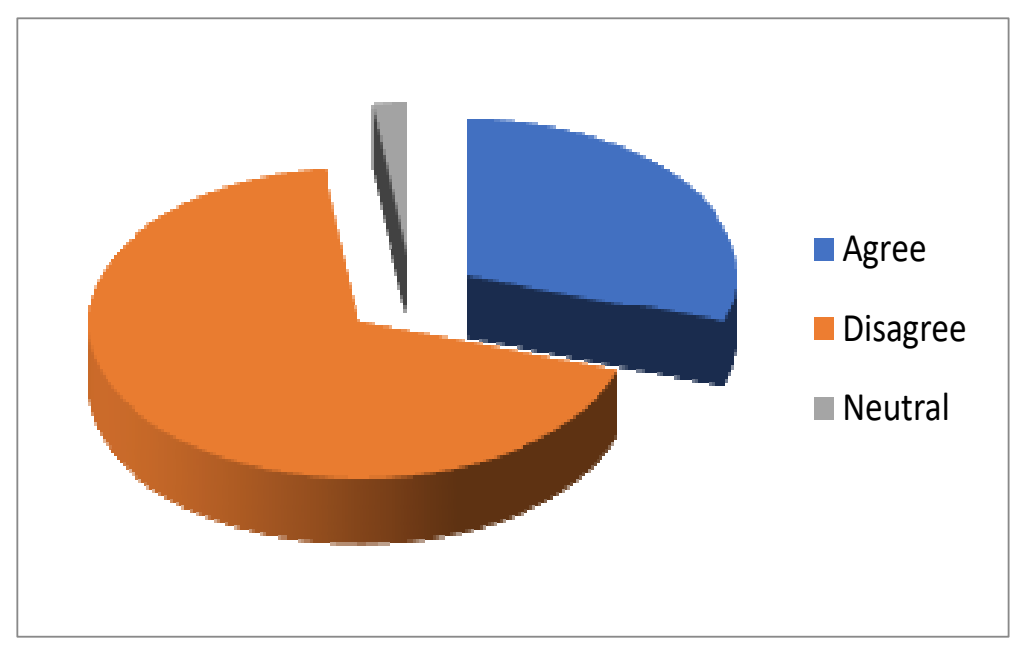

On the issue of successfully solving the issue of child labor, 68 percent of the respondents were of the view that the labor policies and administration in Pakistan have been failed to improve the condition, 30 percent of the respondents were of the opposite view and argued that the situation may not be excellent but at least moving in the fight direction and the conditions have significantly improved over the period of time. Whereas on the issue of resolving the issue of gender discrimination, 78 percent of the respondents were of the view that the labor policies and administration in Pakistan have been failed to improve the condition, 18 percent of the respondents were of the opposite view and argued that the situation may not be excellent but at least moving in the fight direction and the conditions have significantly improved over the period of time.

Majority of the respondents believe that despite boasting about the claims, labor administration have been failed to design and implement a true a labor policy that can be considered as a savior to the weaker gender of the society and to our future our children. The success of the policy could be gauged from the fact still today if one walks through the urban streets or meander through the rural fields, the cute faces of children working hard for their today under toughest of condition, totally unaware about their future. The eyes totally empty of dreams and hands filled with the burdens of life. Female workforce in Pakistan still has to work with worst of circumstances and at times not even been given the status of human. They stressed that on the back of the lower literacy, poor health, poverty, insecurity, and shelter how can it be considered that the labor policies have been able successfully dealt with the daemon of gender discrimination and child labor. On the contrary, those respondents who believe that the situation of gender discrimination and child labor has improved argued that the picture is not as gloomy as it appears. Form their perspective the realization of the problem itself indicates that the situation is heading towards solution. Even though it cannot be said that gender discrimination and child labor has been eliminated but significant improvements are visible in the society. Increase instances of identifying gender discrimination and child labor as a serious problem, more in depth analysis of the issues and proposed policy frameworks to solve the matter and enhanced focus on execution and implementation of those 
policies reflect that pace might be slow but focus is clear. Some of the respondents even felt that the areas of improvements have been identified and soon the economy would be able part its way from gender discrimination and child labor and be able to give its female a glowing face and its children dream filled eyes and hands full of energy to take on future challenge.

\section{Conclusion}

The research paper attempted to find out the causes of the various issues relating to labor policies and child labor, particularly the pathetic conditions the child labor has to experience in Pakistan. The labor and industrial policies, like various other policies linked with sectors like health, education and legal sectors, need significant reforms and updating to become in line with the global standards set for these sectors. The economic condition of Pakistan coupled with its unevenly increasing population make these challenges appear with more gravity. The researcher is convinced that most of the labor bears very low or no literacy, which develops an unhealthy image of the common labor in the society. This also causes a visible division among the people, and has developed strata among them in terms of economic well-being or adversity. The research paper finds the political system holding a very large capacity of improvement. The systems and procedures of the political system, deliberately or knowingly, support lowering of the life standards of the labor. A similar phenomenon proves true for the child labor as well. Even the existing policies for labor lack proper implementation which creates a general impression among the people that governments in Pakistan have consistently neglected the labor. Labor laws need serious review. The element of political instability has also been instrumental in distracting the governments from concrete labor reforms. The consequences of this neglect have been highly harmful because the economic adversity has given rise to crimes in the society.

The researcher agrees to the opinion of the majority of the survey respondents which suggests an authoritarian style of labor administration as this style will prove effective instead of a democratic style which will prove success only when most of the people are literate and conscious about their duties and rights as citizens. The history shows several nations emerging out of crucial crises and then establish themselves in the world. The present imbalance in the labor policies and their implementation in Pakistan can be minimized and set right with the help of appropriate policy reforms and determined implementation. Responsible observance of human rights will be helpful in significant reduction in the mass of child labor. Children laced with literacy and education can be transformed into useful human resource to help establish and maintain socio-economic and political stability in Pakistan.

\section{References}

Bhargava, G. (2003), Child Labour, Gyan Publishing House.

Christopher Charland, Labor Democratization in India and Pakistan, Routledge, 2007.

DAWN, (2016). Child labour increases in Pakistan while numbers drop internationally, retrieved from http://www.dawn.com/news/1233219

Flanagan, R. J. (2006), Globalization and Labor Conditions: Workers Conditions and Working Rights in a Global Economy, Oxford University Press, 2006.

Hindman, H. \& Hindman H.D. (2009), The World of Child Labor: An Historical and Regional Survey, M. E. Sharpe, N.Y.

https://en.wikipedia.org/wiki/Child_labour_in_Pakistan

https://www.ma-law.org.pk/pdflaw/FACTORIES\%20ACT\%201934.pdf ret. 10 November 2018

ILO Report, International Labor Organization Combating Child Labor through Education, Geneva, 2003.

Mathias, P. Nikolaj, T. (2005), History of Humanity and Cuulural Development, vol. 6, UNESCO.

Nararsaiah, M. L. (2006), Child and Labor Education, Discovery Publishing House, New Delhi, 2006.

Naveen Vadsaria, Child Labor - The Biggest Societal Problem in Pakistan? http://blogs.jpmsonline.com/author/naveen-nizar-ali-vadsaria

Pant, S.C. (1972), Indian Labor Problems, Chaitanya Publishing House.

Scholte, J. A., \& Schnebel, A. (2002), Civil Society and Global Finance, Routledge.

Syed, Jawad, Equal Employment Practices, Pakistan \& Gulf Economist, 2003, pp. 34-37.

www.un.org.pk/pakistans-street-children/ ret. 18 Oct. 2018

Yaruq Malik. (2016). Islamabad.(http://dunyanews.tv/en/SpecialReport/320628- Pakistan-3rd-in-child-andforced-labour-ILO ret: 20 Nov. 2018) 